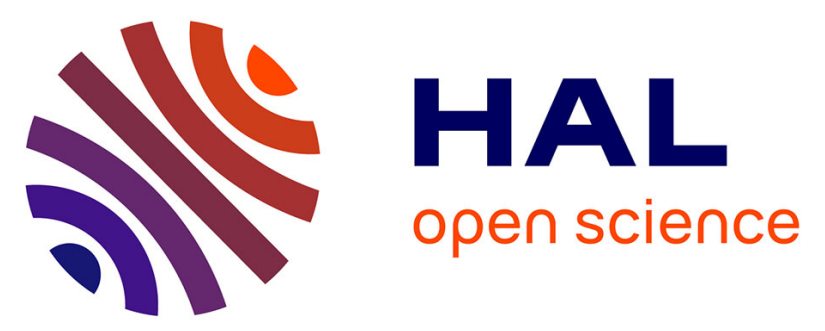

\title{
Influence of manufacturing parameters on the mechanical properties of projection stereolithography-manufactured specimens
}

Danilo Ambrosio, Xavier Gabrion, Pierrick Malecot, Fabien Amiot, Sébastien Thibaud

\section{To cite this version:}

Danilo Ambrosio, Xavier Gabrion, Pierrick Malecot, Fabien Amiot, Sébastien Thibaud. Influence of manufacturing parameters on the mechanical properties of projection stereolithography-manufactured specimens. International Journal of Advanced Manufacturing Technology, 2019, 105, pp.1 - 13. hal02401689

\section{HAL Id: hal-02401689 \\ https://hal.science/hal-02401689}

Submitted on 10 Dec 2019

HAL is a multi-disciplinary open access archive for the deposit and dissemination of scientific research documents, whether they are published or not. The documents may come from teaching and research institutions in France or abroad, or from public or private research centers.
L'archive ouverte pluridisciplinaire HAL, est destinée au dépôt et à la diffusion de documents scientifiques de niveau recherche, publiés ou non, émanant des établissements d'enseignement et de recherche français ou étrangers, des laboratoires publics ou privés. 


\section{The International Journal of Advanced Manufacturing Technology Influence of manufacturing parameters on the mechanical properties of projection stereolithography-manufactured specimens \\ --Manuscript Draft--}

\begin{tabular}{|c|c|}
\hline Manuscript Number: & JAMT-D-19-01633R1 \\
\hline Full Title: & $\begin{array}{l}\text { Influence of manufacturing parameters on the mechanical properties of projection } \\
\text { stereolithography-manufactured specimens }\end{array}$ \\
\hline Article Type: & Original Research \\
\hline Keywords: & $\begin{array}{l}\text { additive manufacturing; projection stereolitography; Material properties; polymer like } \\
\text { materials }\end{array}$ \\
\hline Corresponding Author: & $\begin{array}{l}\text { Sébastien Thibaud, Ph.D. } \\
\text { Univ Bourgogne Franche-Comté } \\
\text { Besançon, FRANCE }\end{array}$ \\
\hline \multicolumn{2}{|l|}{$\begin{array}{l}\text { Corresponding Author Secondary } \\
\text { Information: }\end{array}$} \\
\hline Corresponding Author's Institution: & Univ Bourgogne Franche-Comté \\
\hline \multicolumn{2}{|l|}{$\begin{array}{l}\text { Corresponding Author's Secondary } \\
\text { Institution: }\end{array}$} \\
\hline First Author: & Danilo Ambrosio, Ph.D Student \\
\hline \multicolumn{2}{|l|}{ First Author Secondary Information: } \\
\hline \multirow[t]{5}{*}{ Order of Authors: } & Danilo Ambrosio, Ph.D Student \\
\hline & Gabrion Xavier, Ph.D. \\
\hline & Pierrick Malécot, Ph.D. \\
\hline & Fabien Amiot, Ph.D. \\
\hline & Sébastien Thibaud, Ph.D. \\
\hline \multicolumn{2}{|c|}{ Order of Authors Secondary Information: } \\
\hline Funding Information: & $\begin{array}{l}\text { ERASMUS+ 2018-18 } \\
\text { (2017-1-IT02-KA103-035320) }\end{array}$ \\
\hline Abstract: & $\begin{array}{l}\text { This study focuses on the impact of different fabrication parameters (build orientation, } \\
\text { layer thickness and post-curing time) on the mechanical properties of parts fabricated } \\
\text { through projection stereolithography technology. A Titan } 2 \text { HR printer (Kudo3D Inc.C) } \\
\text { is used to print the specimens. Three different resins have been investigated. } \\
\text { Specimens have been organised in } 7 \text { families for each material. Besides the different } \\
\text { chemical composition of the resins, the results globally show that the most influential } \\
\text { factor on the mechanical properties (ultimate tensile strength, Young's modulus, } \\
\text { elongation at break) is the build orientation. Contrarily, the effect of the post-curing time } \\
\text { has proved to be highly dependent on the chemical composition of polymers, playing a } \\
\text { significant role only for resins that do not complete the polymerization process during } \\
\text { printing and therefore require a subsequent treatment time. }\end{array}$ \\
\hline
\end{tabular}




\section{List of responses}
D. Ambrosio
X. Gabrion
P. Malécot
F. Amiot

S. Thibaud.

sebastien.thibaud@ens $2 \mathrm{~m}$.fr

September 4, 2019

\section{Reviewer \#1}

\#1 English is OK, but still can be polished

Several modifications have been made to improve the language.

\#2 In Fig. 2, some dimensions are missing. Cannot design a same part based on the current limited values.

Fig. 2 has been completed with the missing dimensions.

\#3 "Besides the printed materials .... the years [11-19]". For this statement, more works for your reference, "Effect of Support on Printed Properties in Fused Deposition Modelling Processes".

The reference has been added and the paragraph has been extended.

\#4 In the introduction part, the authors should introduce the background that fabrication parameters can not only influence the mechanical properties, but also accuracy, printability...".

Two references have been added to explain that manufacturing parameters can influence the geometry of printed parts.

Reviewer \#2: It's a well written paper. I'd like to recommend Accept Reviewer \#3

\#1 The paper is very long while it can be more on point and summarized. For example, the first half of introduction is unnecessary.

The first part of the introduction has been removed. The literature survey on the influence of the building orientation on the mechanical parts has also been further summarized.

\#2 The design of experiments is not clarified. The last line of Page 4 says "There are 3 specimens in each family" while in the results, only two graphs has been presented for each family. The reason for choosing the parameter values for each family is not mentioned.

Three tests have been performed for each configuration. Only the two extremal curves defining the enveloppe of the results have been displayed on graphs in order to ease their reading. The choice of the studied parameters 
was made according to the literature, which indicated the most interesting parameters to be investigated. The reason for choosing the building orientation, the layer thickness and the post-curing time as parameters has been added to the manuscript.

\#3 Mechanical testing should be carried out based on a defined standard. Instead of a drawing for the sample dimensions, maybe it is better to mention why these dimensions haven been selected or if a standard has been chosen for determining the mechanical testing parameter

Considering the build envelope it was impossible to perform tensile tests according to a standard. The choice of the sample size and geometry was made according to the available building volume, as already indicated in the manuscript, 49*28*200mm3 (xyz). Before running the experimental campaign, preliminary tests were carried out to ensure the rupture of the specimen within the gauge length. The reason for the choice of these dimensions and geometry has been added to the manuscript.

\section{\#4 Figures 4 and 5 are not delivering any extra information.}

Figures 4 and 5 have been removed because not delivering extra information.

\#5 Figure captions should be more comprehensive. They should describe the data shown, draw attention to important features contained within the figure.

Several corrections have been made to the captions in order to ease the comprehension of the reported data. 


\section{fento-st \\ - III SCIENCES \& TECHNOLOGIES}

May 9th, 2017

Subject: publication in Journal Of Advanced Manufacturing Technology

Dear Editor,

I am currently employed as full professor in the University of Bourgogne Franche-Comté, France. My research works take place in the FEMTO-ST Institute of Besançon (Department of Applied Mechanics).

I would like to submit you a manuscript on "Influence of manufacturing parameters on the mechanical properties of projection stereolithography-manufactured specimens". This work is original and:

- The paper is not submitted for publication elsewhere.

- The paper, in its entirety, in part, or in a modified version, has not been published elsewhere.

The main contribution in the field of polymer additive manufacturing parts is based on the influence of manufacturing process on mechanical behavior of projection stereolithography parts. The influence of manufacturing parts are discussed and experiments are done in order to define the influence of process on the obtained parts. Digital image correlation is used to identify mechanical behavior. Experimental study about post processing curing time is also performed. The paper has industrial application associated to the development and design of additive polymer manufactured parts obtained by projection stereolithography processing. The paper allows to define design criteria in relation to manufacturing process.

Sincerely

Pr. Sébastien THIBAUD

University of Bourgogne Franche-Comté

FEMTO-ST Institute

Department of Applied Mechanics

24, rue de l'Epitaphe

25000 Besançon

FRANCE 


\title{
Influence of manufacturing parameters on the mechanical properties of projection stereolithography-manufactured specimens
}

\author{
D. Ambrosio - X. Gabrion • P. Malécot . \\ F. Amiot . S. Thibaud.
}

Received: date / Accepted: date

\begin{abstract}
This study focuses on the impact of different fabrication parameters (build orientation, layer thickness and post-curing time) on the mechanical properties of parts fabricated through projection stereolithography technology. A Titan $2 \mathrm{HR}$ printer (Kudo3D Inc.(C) was used to print the specimens. Three different resins have been investigated. Specimens have been organised in 7 families for each material. Besides the different chemical composition of the resins, the results globally show that the most influential factor on the mechanical properties (ultimate tensile strength, Young's modulus, elongation at break) is the build orientation. Contrarily, the effect of the post-curing time has proved to be highly dependent on the chemical composition of polymers, playing a significant role only for resins that do not complete the polymerization process during printing and therefore require a subsequent treatment time. Layer thickness in this application has shown a relevant influence on the mechanical characteristics of the studied resins.
\end{abstract}

Keywords additive manufacturing · projection stereolithography · material properties

\section{Introduction}

Stereolithography (SLA) represents the first additive manufacturing (AM) techniques commercialized during the mid-1980s and has thus been widely studied [1]. The process is based on the possibility to obtain highly accurate parts starting from photosensitive polymers. SLA machines originally produced parts using a focused ultraviolet laser beam that selectively initiated the photopolymerization process in the liquid photopolymer contained in a vat, with the final parts being obtained layer by layer. An elevator platform step by step decreases the build platform position, depending on the chosen layer thickness exposing every step a new layer of photopolymer ready to be photopolymerized to the UV laser beam

S. Thibaud

FEMTO-ST Institute, Univ. Bourgogne-Franche-Comté, ENSMM, F-25000 Besançon, France E-mail: sebastien.thibaud@ens2m.fr 
$[2-7]$.

New devices based on the same chemical principle, such as the projection stereolithography (PSL), have then been developed (Fig.1).

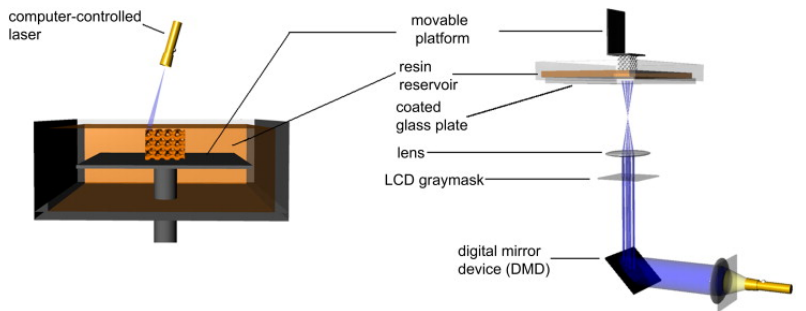

Fig. 1 Schemes of two types of stereolithography setups. Left: top-down system with scanning laser. Right: bottom-up setup with digital light projection [5].

This new technique substitutes the focused laser beam with a UV light projector that allows to photopolymerize one layer at once avoiding the problem to choose the path of the laser beam and decreasing the execution time to obtain a single layer. The photopolymerization of the single layer is obtained thanks to a dynamic mask that is projected onto a new resin's layer at each step, thanks to the movement of the build platform, determining the photopolymerization only of the cross-section of the dynamic mask [7-10].

Mechanical properties of 3D-printed parts can be affected by both the material properties and the manufacturing method. Besides the printed materials, many analyses concerning various additive manufacturing techniques and related manufacturing parameters that may affect the mechanical properties of the printed part have been proposed over the years [11-20]. Similarly, several studies concerning the effect of manufacturing parameters on the geometry of 3D-printed parts have been proposed [21,22].

An exhaustive analysis of various additive manufacturing techniques for polymers and related manufacturing parameters that affect the mechanical properties of a part has been proposed by Dizon et al. [11]. The authors showed through this review that mechanical properties of 3D-printed parts are closely linked to various manufacturing parameters.

Among these, build orientation has been one of the most studied manufacturing parameters [12-15]. Quintana et al. [12] showed that printing direction has a statistically significant effect on mechanical properties of SLA 3D printed parts. Domínguez-Rodríguez et al. [13] studied the influence of printing direction on the mechanical behaviour of specimens manufactured by fused deposition modeling (FDM) under uniaxial compression. The authors claimed that higher strength and stiffness were achieved with specimens printed along the longitudinal direction. Influence of the build orientation on the shear properties of 3D-printed parts has been proven by Rohde et al. [14]. Abid et al. [15] investigated the influence of manufacturing direction in FDM printed parts. The results obtained through statistical analysis showed that the manufacturing direction has a strong effect on yield stress and tensile strength. Also, the effects of support strategy on FDM printed mechanical properties has been shown by Jiang et al. [16].

Even though less information is available compared to the build orientation, the 
layer thickness has also been shown to affect the mechanical properties of the parts $[17,18]$. 3D-printed parts through SLA are influenced by layer thickness, as demonstrated by Chockalingam et al. [17]. The authors, investigated layer thicknesses of $100 \mu \mathrm{m}, 125 \mu \mathrm{m}$ and $150 \mu \mathrm{m}$ revealing that the smaller the layer thickness, the higher the strength of the part. Rankouhi et al. [18] showed that layer thickness largely affects the mechanical properties of parts manufactured out of ABS using FDM. Specifically, specimens printed with a smaller layer thickness $(0.2 \mathrm{~mm})$ showed higher stiffness and ultimate tensile strength compared to specimens fed using thicker layers $(0.4 \mathrm{~mm})$.

The post-curing can also influence the mechanical properties of a part $[19,20]$. Chantarapanich et al. [19] investigated the influence of the post-curing time on specimens printed through SLA. The authors observed that the mechanical strength of specimens can be improved increasing the UV post-curing period from 0 to 4 hours whereas, above 4 hours, the mechanical properties of specimens were nearly constant. Hague et al. [20] also studied the effect of the post-curing on the mechanical properties of SLA parts. The authors found out that varying the post-curing methodology would affect the mechanical properties of the printed parts.

Although, many researchers have studied the influence of manufacturing parameters on 3D-printed parts in SLA and FDM technologies, a similar investigation for PSL is still lacking. Objectives of this study are therefore the understanding of the influence of the chosen manufacturing parameters on the mechanical properties of the individual resins and then the evaluation of the overall effect of these process parameters, to highlight whether their effect is independent of the type of resin or not. The potential different impact of the process parameters on the resins' mechanical characteristics would make this type of characterization necessary for each different resin used in a specific application.

\section{Manufacturing process}

\subsection{Material}

The following investigation focuses on the mechanical characteristics of specimens manufactured in different ways using commercial stereolithography (SLA) digital light processing (DLP) 3D printer (Titan 2 HR, Kudo3D Inc.(C). Specifically, the comparison has been carried out on three different photosensitive resins characterised by different chemical characteristics:

- S-PRO Engineering - High Performance (Spot-A Materials) (Aliphatic acrylates, cycloaliphatic acrylates, aromatic acrylate oligomer, epoxy-acrylate oligomer and bis(methylene) diacrylate) [23];

- 3DM - X-GREEN resin (3DM Materials) (Mixture of acrylic acid esters, acrylated monomers, oligomers and photoinitiators) [24];

- 3DM - ABS resin (3DM Materials) (Mixture of (meth)acrylic acid esters, (meth)acrylated monomers, oligomers and photoinitiators) [25];

The resins are designed for PSL systems, (405 nm wavelength) with a different set of parameters for each resin. The resolution used to print all the samples, in the $\mathrm{x}-\mathrm{y}$ plane (printing plane), is $25 \mu \mathrm{m}$, which is the best achievable with this device. 


\subsection{Methods}

The specimen has been modelled in CAD software and all of them have been fabricated on the $3 \mathrm{D}$ printer changing the processing parameters for each resin. The volume of the building envelop for the machine is $49 \mathrm{~mm}$ x $28 \mathrm{~mm}$ x $200 \mathrm{~mm}$. The specimen geometry is shown in the Fig.2. The dimensions and geometry were chosen according to the build envelope. Before running the experimental campaign, preliminary tests were carried out to ensure the rupture of the specimen within the gauge length.

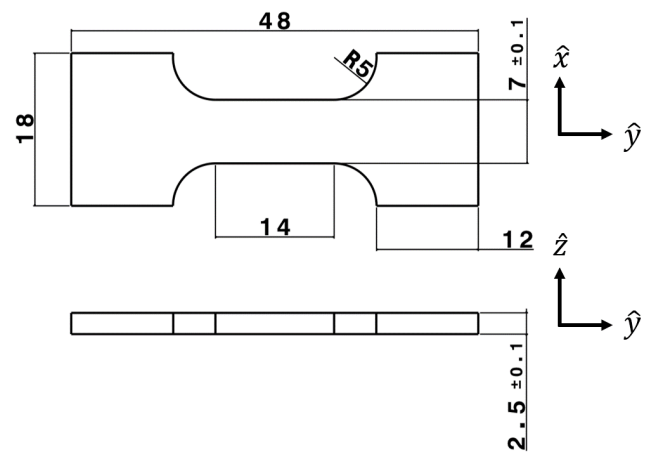

Fig. 2 Specimen dimensions $(\mathrm{mm})$.

The effect of layer thickness, build orientation and post-curing time on the mechanical properties has been investigated. The process parameters were chosen because they are very likely to have an impact on mechanical properties, as already seen for other AM techniques.

Three types of build orientation are considered (Fig.3):

- Longitudinal (along the y axis) (a);

- Transverse (along the $\mathrm{x}$ axis) (b);

- Normal (along the z axis) (c);

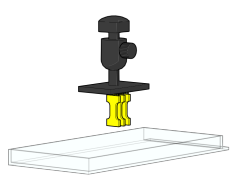

a.

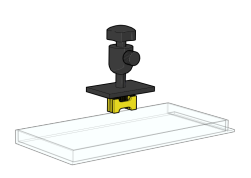

b.

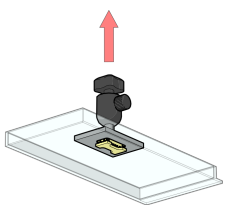

c.

Fig. 3 Different build orientations: a) longitudinal, b) transverse, c) normal.

The building volume allows to print 3 specimens at the same type when printing along the $\mathrm{x}$ and $\mathrm{y}$-direction, and one for the $\mathrm{z}$-direction. Samples were organized 
Table 1 Manufacture scheme

\begin{tabular}{llll}
\hline Family & Orientation & Layer Thickness $(\mu \mathrm{m})$ & Post-curing $(\mathrm{h})$ \\
\hline L-1 & Longitudinal & 100 & 1 \\
L-1 & Longitudinal & 50 & 1 \\
T-1 & Transverse & 100 & 1 \\
N-1 & Normal & 100 & 1 \\
L-2 & Longitudinal & 100 & 2 \\
L-3 & Longitudinal & 100 & 3 \\
L-4 & Longitudinal & 100 & 4 \\
\hline
\end{tabular}

into 7 families. There are 3 specimens in each family, as described in Table 1 . The letter indicates the printing direction, the number indicates the post-curing time (hour) and the eventual bar on the number refers to a modification of the layer thickness. The family L-1 gathers the reference samples, and the other families are used to study the effect of the 3 factors.

\subsection{Mechanical Testing}

The uniaxial tensile tests have been performed using MTS Criterion® Electromechanical Universal Test Systems machine with a load cell of $1 \mathrm{kN}$. The strain rate was set to $40 \cdot 10^{-6} \mathrm{~s}^{-1}$ for the S-PRO and ABS and $80 \cdot 10^{-6} \mathrm{~s}^{-1}$ for the $\mathrm{X}$-GREEN, at room temperature $21^{\circ} C\left( \pm 1^{\circ} C\right)$. The gauge part of the specimen for the strain measurement is $12 \mathrm{~mm}$ in length. Young's modulus (E) (MPa), ultimate tensile strength (UTS) (MPa), elongation at break $\left(\varepsilon_{b}\right)$ and Poisson's ratio $(\nu)$ have been measured for all specimens. E was determined from a least squares linear regression of the measured data between $1 \%$ and $3 \%$ strain. The strength was calculated as the load divided by the cross section.

A random pattern has been spray-painted onto the specimens. A camera Point Grey 4 Megapixel equipped with a telecentric lens that prevents measurements from optical distortions was used to acquire images. Image acquisition was triggered at a rate of 1 frame per sec. DIC was performed with VIC-2D software, calculating the displacements from the acquired pictures. Strains in the longitudinal and transverse direction have been calculated as described in [26]. All the data obtained have been used to show the engineering stress-strain curves of the different tests. Only the two extremal curves defining the enveloppe of the results have been displayed on graphs in order to ease their reading. The percentage variation of E, UTS and elongation at break between families L-1 and L- 1 , L-1, T-1 and N-1 and L-1, L-2, L-3 and L-4, for all the resins are available in the Appendix.

\section{Results}

\subsection{S-PRO resin}

\subsubsection{Build Orientation}

Considering that the PSL technique is based on the layer manufacturing concept, the build orientation is expected to influence the mechanical properties of the 
Table 2 Average values and standard deviation of Young's modulus, ultimate tensile strength, elongation at break and Poisson's ratio for S-PRO families L-1, T-1 and N-1.

\begin{tabular}{lllll}
\hline $\begin{array}{l}\text { Orientation } \\
\text { S-PRO }\end{array}$ & $\begin{array}{l}\text { E } \\
(\mathrm{MPa})\end{array}$ & $\begin{array}{l}\text { UTS } \\
(\mathrm{MPa})\end{array}$ & $\begin{array}{l}\text { Elong. break } \\
(\%)\end{array}$ & $\boldsymbol{\nu}$ \\
\hline $\mathbf{L - 1}$ & $1557 \pm 38$ & $29.7 \pm 1$ & $16.2 \pm 3$ & $0.41 \pm 0.01$ \\
$\mathbf{T}-\mathbf{1}$ & $2019 \pm 112$ & $35.0 \pm 1$ & $11.4 \pm 2$ & $0.42 \pm 0.03$ \\
$\mathbf{N}-\mathbf{1}$ & $1980 \pm 88$ & $30.0 \pm 1$ & $5.5 \pm 2$ & $0.44 \pm 0.01$ \\
\hline
\end{tabular}

material. Fig.4 displays typical stress-strain curves obtained for S-PRO samples belonging to families L-1, T-1 and N-1.

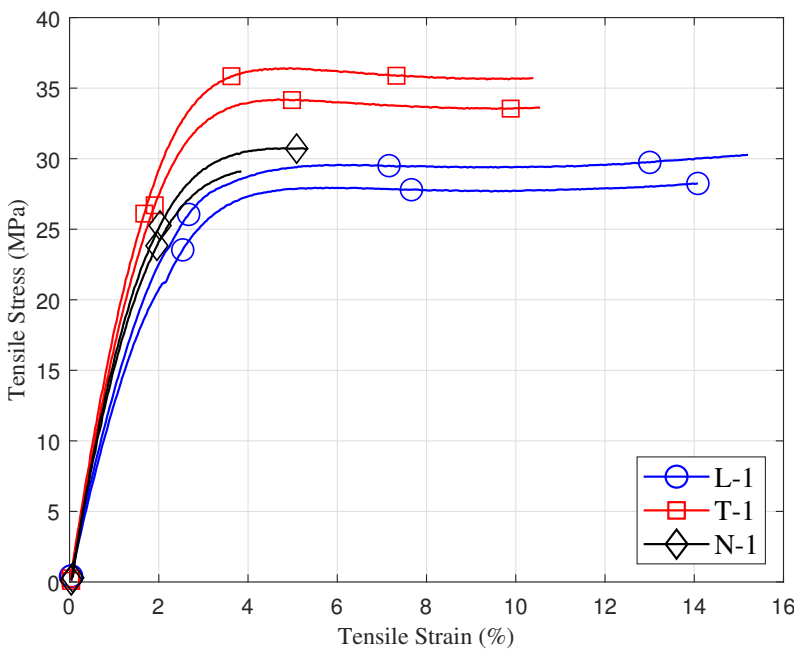

Fig. 4 Stress-strain curves for S-PRO families L-1, T-1 and N-1. Effect of the build orientation.

Samples from these families exhibit rather different behaviours. Specimens built along the longitudinal direction display a large plasticity regime, with an elongation at break $\varepsilon_{b}=15 \%$. Samples built along the transverse direction display higher yield stress with a smaller elongation at break $\left(\varepsilon_{b}=10 \%\right)$. Finally, for samples obtained by building along the normal direction, the elongation at break is $5 \%$ which corresponds to the onset of plasticity.

Table 2 summarizes the results obtained with 9 samples. The transverse configuration shows the best mechanical characteristics with significantly increased Young's modulus and UTS. It is interesting to observe that the lower rigidity configuration is represented by the longitudinal one, that means that having the layers perpendicular to the load direction minimizes the Young's modulus.

\subsubsection{Layer Thickness}

The layer thickness and, as a consequence, the number of layers could also influence the mechanical properties of the material. Fig.5 displays the stress-strain curves for families L- 1 and L- $\overline{1}$, corresponding to the layer thickness of 100 and 50 
Table 3 Average values and standard deviation of Young's modulus, ultimate tensile strength, elongation at break and Poisson's ratio for S-PRO families L-1 and L- $\overline{\mathbf{1}}$.

\begin{tabular}{lllll}
\hline $\begin{array}{l}\text { Layer Thickness } \\
\text { S-PRO }\end{array}$ & $\begin{array}{l}\mathbf{E} \\
(\mathrm{MPa})\end{array}$ & $\begin{array}{l}\text { UTS } \\
(\mathrm{MPa})\end{array}$ & $\begin{array}{l}\text { Elong. break } \\
(\%)\end{array}$ & $\boldsymbol{\nu}$ \\
\hline $\mathbf{L - 1}$ & $1557 \pm 38$ & $29.7 \pm 1$ & $16.2 \pm 3$ & $0.41 \pm 0.01$ \\
$\mathbf{L - 1}$ & $1569 \pm 104$ & $29.3 \pm 0.6$ & $15.8 \pm 2$ & $0.40 \pm 0.04$ \\
\hline
\end{tabular}

$\mu \mathrm{m}$ respectively. No significant difference in the response of the material can be observed. The behaviour is almost the same, and the differences are very limited compared to the results obtained from the build orientation.

Table 3 shows average values and standard deviation for Young's modulus, UTS, elongation at break and Poisson's ratio.

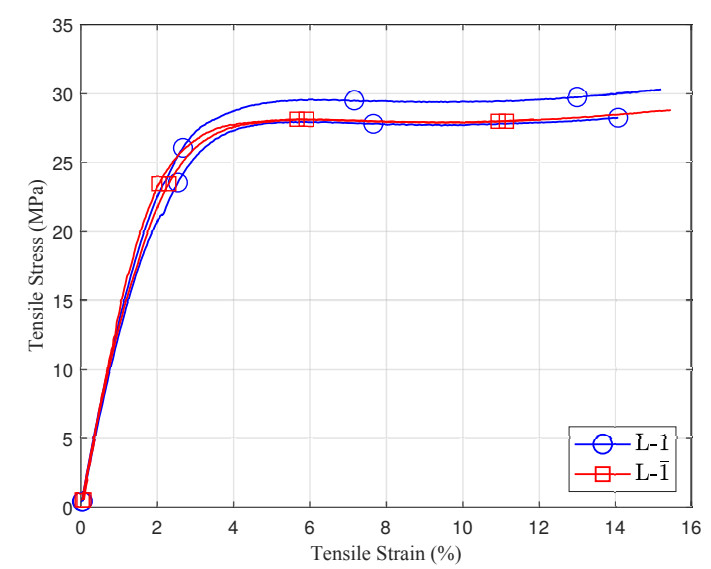

Fig. 5 Stress-strain curves for S-PRO families L-1 and L-1. Effect of the layer thickness.

\subsubsection{Post-curing}

As most of the additive manufacturing techniques, the parts manufactured through PLS require to be exposed to UV light to complete the polymerisation process. Specimens with 4 different post-curing times are compared herein. Both surfaces of each specimen have been exposed to the UV light for the same time, so the amount indicated in the legend has to be split between the two sides. Fig. 6 displays the mechanical responses for families L-1, L-2, L-3, L-4.

UTS is not particularly influenced by the exposure time as shown in Fig.7. Increasing the exposure time guarantees a general improvement of all the mechanical properties until 4 hours as shown in Fig.8.

A decrease in the elongation at break is also shown so that increasing the exposition time at the UV induces embrittlement of the material. Table 4 shows average values and standard deviation for Young's modulus, UTS, elongation at break and Poisson's ratio. 


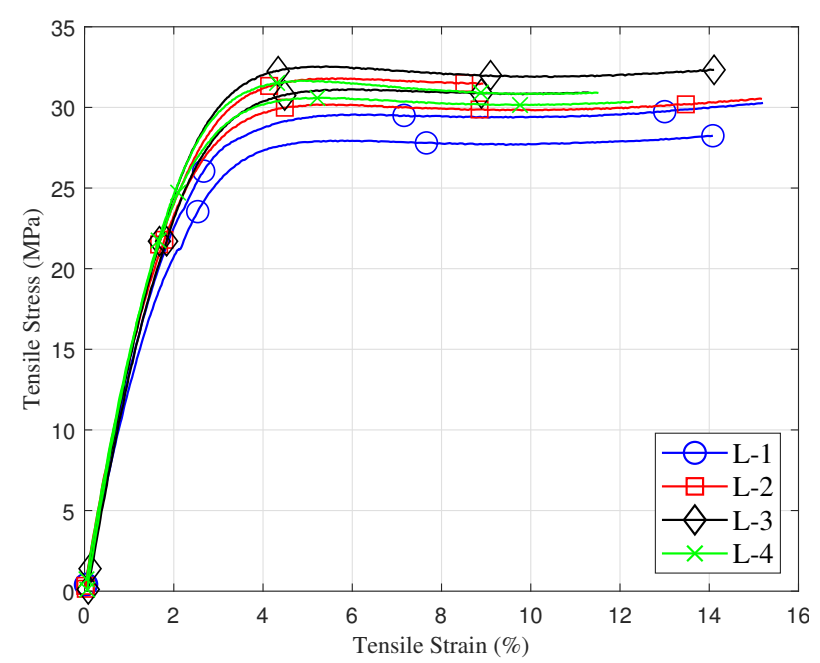

Fig. 6 Stress-strain curves for S-PRO families L-1, L-2, L-3 and L4. Effect of the post-curing time.

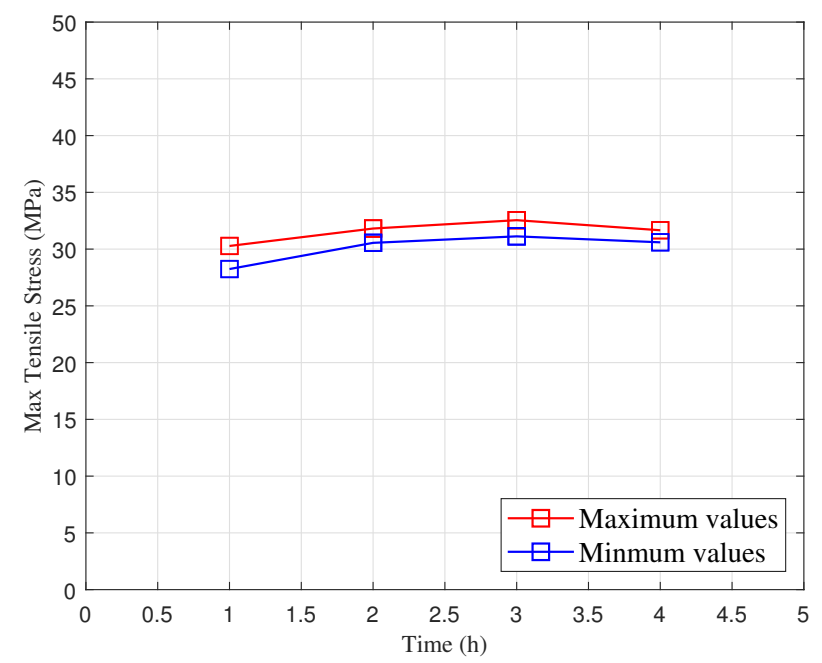

Fig. 7 Evolution of the ultimate tensile strength as a function of the post-curing time for S-PRO.

\subsection{X-GREEN resin}

\subsubsection{Build Orientation}

Fig.9 shows the stress-strain curves obtained for X-GREEN samples built along the different directions. The response exhibits peak stress at the yield, and then a stress decrease when entering the plastic regime. The peak is very weak for the longitudinal direction and is more visible for the normal and transverse directions. It is interesting to observe a softening effect in the plastic regime. This behaviour is linked to a specific phenomenon occurring during the necking. The material in the 


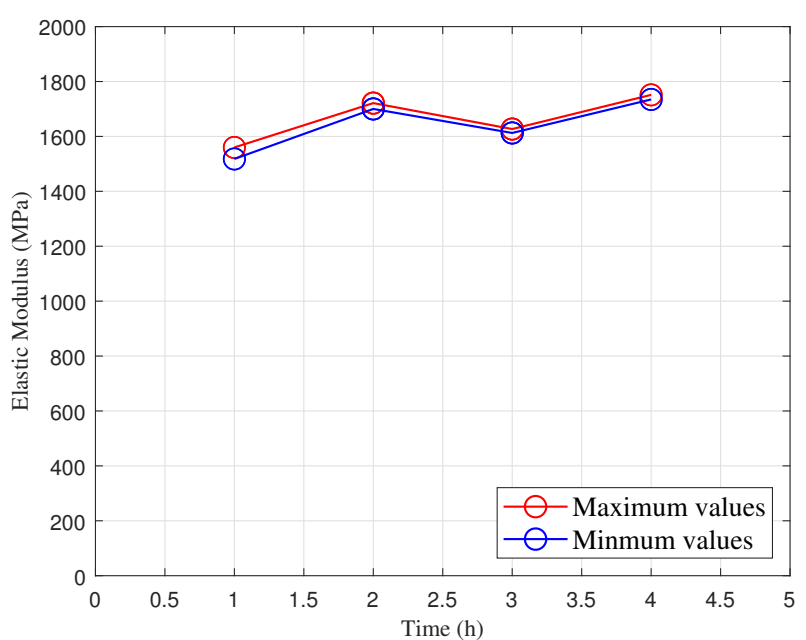

Fig. 8 Evolution of the Young's modulus as a function of the post-curing time for S-PRO.

Table 4 Average values and standard deviation of Young's modulus, ultimate tensile strength, elongation at break and Poisson's ratio for S-PRO families L-1, L-2, L-3 and L4.

\begin{tabular}{lllll}
\hline $\begin{array}{l}\text { Post-curing time } \\
\text { S-PRO }\end{array}$ & $\begin{array}{l}\text { E } \\
(\mathrm{MPa})\end{array}$ & $\begin{array}{l}\text { UTS } \\
(\mathrm{MPa})\end{array}$ & $\begin{array}{l}\text { Elong. break } \\
(\%)\end{array}$ & $\boldsymbol{\nu}$ \\
\hline L-1 & $1557 \pm 38$ & $29.7 \pm 1.3$ & $16.2 \pm 2.7$ & $0.41 \pm 0.01$ \\
L-2 & $1711 \pm 15$ & $31.2 \pm 0.8$ & $12.1 \pm 4.4$ & $0.46 \pm 0.01$ \\
L-3 & $1655 \pm 61$ & $32.2 \pm 0.9$ & $13.8 \pm 2.4$ & $0.48 \pm 0.02$ \\
L-4 & $1697 \pm 80$ & $30.9 \pm 0.7$ & $11.7 \pm 0.6$ & $0.44 \pm 0.03$ \\
\hline
\end{tabular}

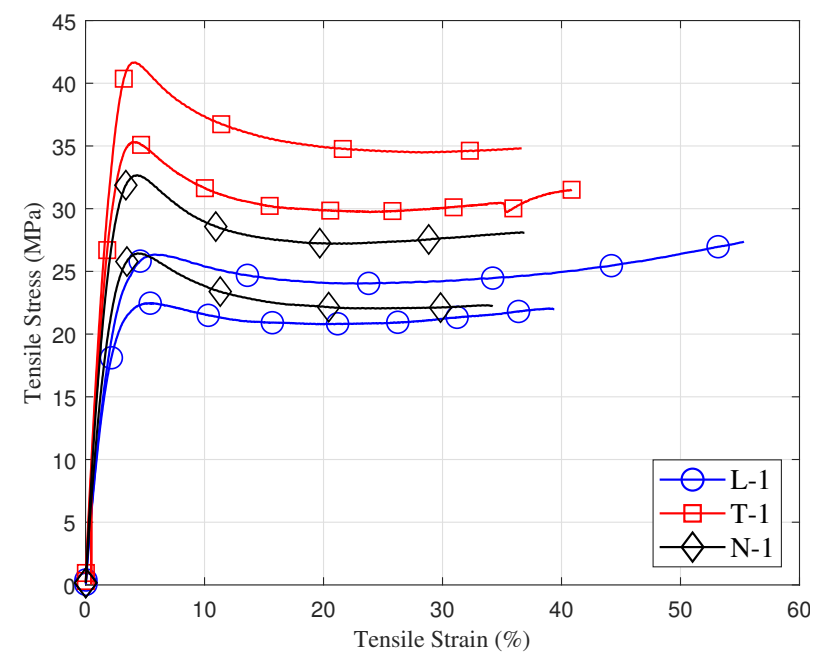

Fig. 9 Stress-strain curves for X-GREEN families L-1, T-1 and N-1. Effect of the build orientation.

neck stretches only to a "natural draw ratio" which is a function of temperature 
Table 5 Average values and standard deviation of Young's modulus, ultimate tensile strength, elongation at break and Poisson's ratio for X-GREEN families L-1, T-1 and N-1.

\begin{tabular}{lllll}
\hline $\begin{array}{l}\text { Orientation } \\
\text { X-GREEN }\end{array}$ & $\begin{array}{l}\text { E } \\
(\mathrm{MPa})\end{array}$ & $\begin{array}{l}\text { UTS } \\
(\mathrm{MPa})\end{array}$ & $\begin{array}{l}\text { Elong. break } \\
(\%)\end{array}$ & $\boldsymbol{\nu}$ \\
\hline $\mathbf{L - 1}$ & $1270 \pm 83$ & $24.7 \pm 2.5$ & $43.6 \pm 10.3$ & $0.40 \pm 0.02$ \\
$\mathbf{T - 1}$ & $1945 \pm 52$ & $38.7 \pm 1$ & $35.7 \pm 8.2$ & $0.40 \pm 0.02$ \\
$\mathbf{N - 1}$ & $1748 \pm 143$ & $30.1 \pm 3.3$ & $35.1 \pm 1.6$ & $0.40 \pm 0.01$ \\
\hline
\end{tabular}

and specimen processing, beyond which the material in the neck stops stretching and new material at the neck shoulders necks down. The neck then propagates until it spans the full gauge length of the specimen. This process is called drawing. Not all polymers are able to sustain this drawing process. It occurs when the necking process produces a strengthened microstructure whose breaking load is greater than that needed to induce necking in the untransformed material just outside the neck [27].

The mechanical properties are shown in Table 5. The transverse configuration features the best mechanical properties; Young's modulus and UTS are clearly increased compared to the longitudinal configuration (more than 50\% higher). The build orientation, however, does not significantly alter the high ductility of the material.

\subsubsection{Layer Thickness}

The influence of the layer thickness for X-GREEN specimens is shown in Fig.10. Significant differences can be noticed between the two configurations. A lower layer

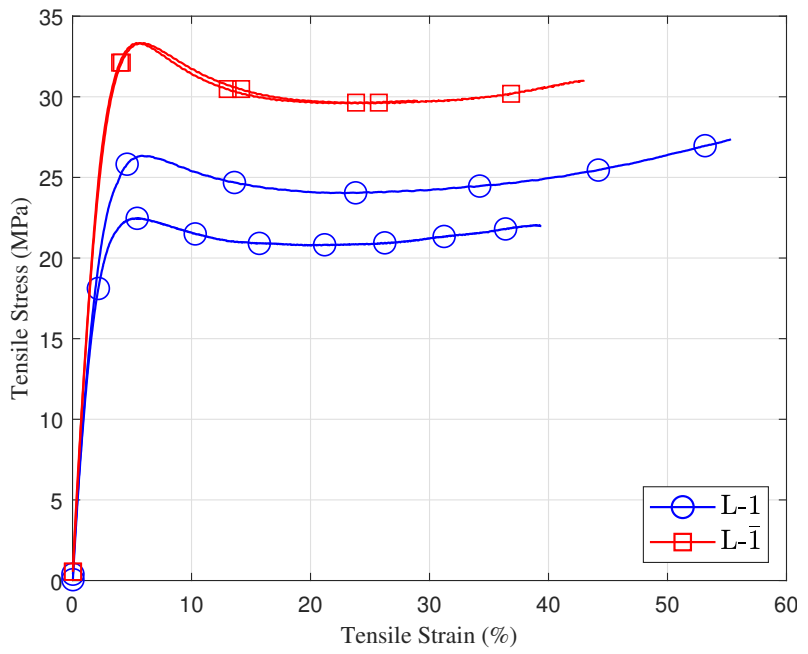

Fig. 10 Stress-strain curves for X-GREEN families L-1 and L-1̄. Effect of the layer thickness.

thickness, and consequently a higher number of layers, increases the mechanical properties of the material. Both curves, however, display strain-softening after the 
Table 6 Average values and standard deviation of Young's modulus, ultimate tensile strength, elongation at break and Poisson's ratio for X-GREEN families L-1 and L-ī.

\begin{tabular}{lllll}
\hline $\begin{array}{l}\text { Layer Thickness } \\
\text { X-GREEN }\end{array}$ & $\begin{array}{l}\text { E } \\
(\mathrm{MPa})\end{array}$ & $\begin{array}{l}\text { UTS } \\
(\mathrm{MPa})\end{array}$ & $\begin{array}{l}\text { Elong. break } \\
(\%)\end{array}$ & $\boldsymbol{\nu}$ \\
\hline $\mathbf{L - 1}$ & $1270 \pm 83$ & $24.7 \pm 2.5$ & $43.6 \pm 10.3$ & $0.40 \pm 0.02$ \\
$\mathbf{L - 1}$ & $1456 \pm 71$ & $33.0 \pm 0.6$ & $39.1 \pm 8.7$ & $0.42 \pm 0.01$ \\
\hline
\end{tabular}

yield stress value and a beginning strain-hardening before the rupture. Table 6 shows average values and standard deviation of Young's modulus, UTS, elongation at break and Poisson's ratio of the specimens. For this resin, 20\% and $13 \%$ difference in strength and elastic modulus are respectively measured between the two configurations.

\subsubsection{Post-curing}

The post-curing effect can be analysed from the stress-strain curves shown in Fig.11.

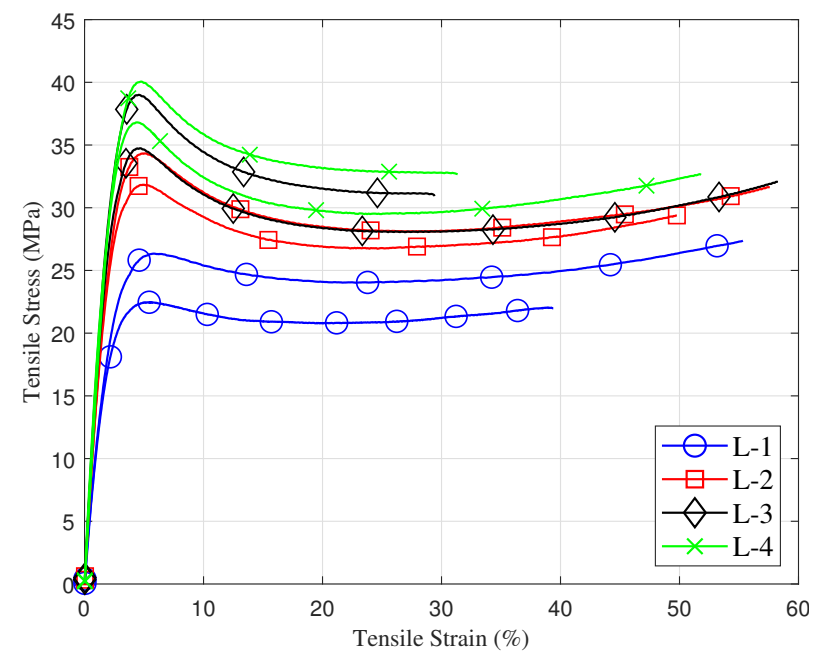

Fig. 11 Stress-strain curves for X-GREEN families L-1, L-2, L-3 and L4. Effect of the postcuring time.

UTS and Young's modulus are reported in Fig.12 and Fig.13 respectively. Increasing the post-curing time until 4 hours benefits all the material properties. Comparing UTS and Young's modulus for L-1 and L- 4 families, a $49.3 \%$ and $12.6 \%$ increase can be observed.

Table 7 displays the improvement of the mechanical properties from 1 to 4 hours. The shape of the curves is similar to the one observed in all the previous families, so this polymer is also characterised by strain-softening phenomenon after reaching of the maximum tensile stress and some strain-hardening before the rupture. 


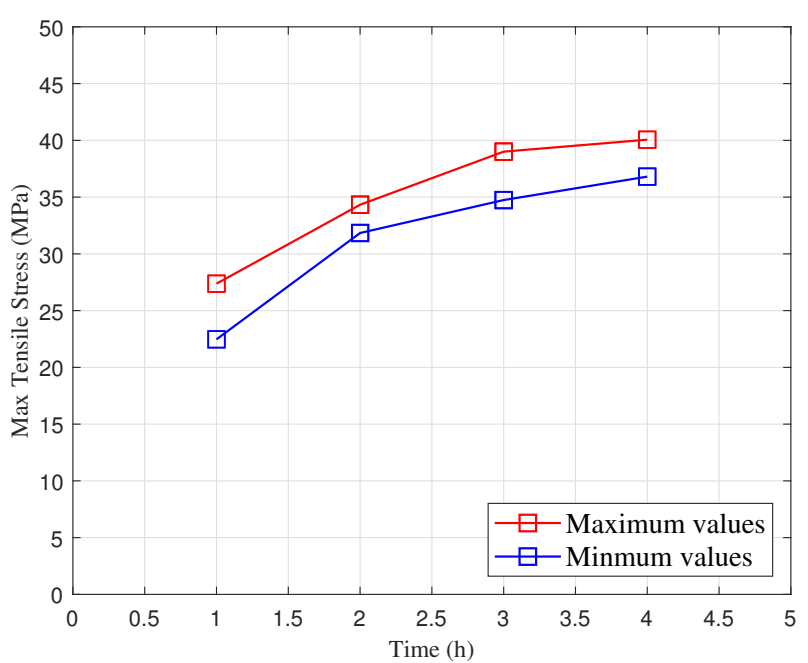

Fig. 12 Evolution of the ultimate tensile strength as a function of the post-curing time for X-GREEN.

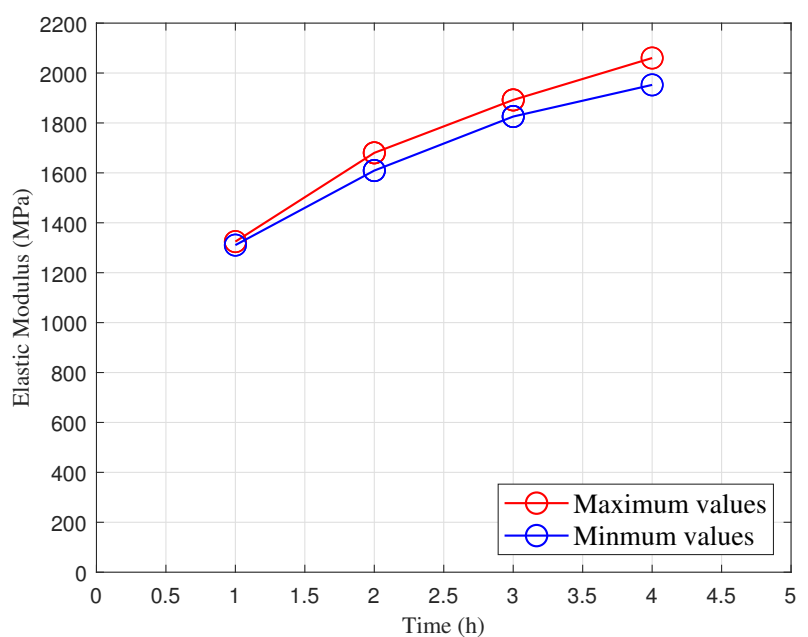

Fig. 13 Evolution of the Young's modulus as a function of the post-curing time for X-GREEN.

\subsection{ABS resin}

\subsubsection{Build Orientation}

The influence of the build orientation, for ABS specimens, is shown in Fig.14. The material's behaviour turns to be brittle, for both transverse and normal configurations, as demonstrated by the drastic decrease of the elongation at break. Specimens manufactured along the normal directions do not show any necking phenomenon and break before any plasticity develop. For the ABS resin, families T-1 and N-1 display a brittle behaviour. This significantly differs from the ductil- 
Table 7 Average values and standard deviation of Young's modulus, ultimate tensile strength, elongation at break and Poisson's ratio for X-GREEN families L-1, L-2, L-3 and L4.

\begin{tabular}{lllll}
\hline $\begin{array}{l}\text { Post-curing time } \\
\text { X-GREEN }\end{array}$ & $\begin{array}{l}\text { E } \\
(\mathrm{MPa})\end{array}$ & $\begin{array}{l}\text { UTS } \\
(\mathrm{MPa})\end{array}$ & $\begin{array}{l}\text { Elong. break } \\
(\%)\end{array}$ & $\boldsymbol{\nu}$ \\
\hline L-1 & $1270 \pm 83$ & $24.7 \pm 2.5$ & $43.6 \pm 10.3$ & $0.40 \pm 0.02$ \\
L-2 & $1578 \pm 120$ & $32.7 \pm 1.4$ & $55.3 \pm 4.7$ & $0.41 \pm 0.02$ \\
L-3 & $1847 \pm 39$ & $36.2 \pm 2.4$ & $45.5 \pm 14.7$ & $0.40 \pm 0.01$ \\
L-4 & $1894 \pm 201$ & $36.9 \pm 3.2$ & $44.5 \pm 11.4$ & $0.40 \pm 0.01$ \\
\hline
\end{tabular}

Table 8 Average values and standard deviation of Young's modulus, ultimate tensile strength, elongation at break and Poisson's ratio for ABS families L-1, T-1 and N-1.

\begin{tabular}{lllll}
\hline $\begin{array}{l}\text { Orientation } \\
\text { ABS }\end{array}$ & $\begin{array}{l}\text { E } \\
(\mathrm{MPa})\end{array}$ & $\begin{array}{l}\text { UTS } \\
(\mathrm{MPa})\end{array}$ & $\begin{array}{l}\text { Elong. break } \\
(\%)\end{array}$ & $\boldsymbol{\nu}$ \\
\hline $\mathbf{L - 1}$ & $1831 \pm 59$ & $35.6 \pm 0.9$ & $13.1 \pm 3.1$ & $0.40 \pm 0.01$ \\
$\mathbf{T - 1}$ & $1820 \pm 82$ & $34.5 \pm 2.6$ & $3.1 \pm 0.7$ & $0.41 \pm 0.01$ \\
$\mathbf{N - 1}$ & $2286 \pm 159$ & $30.2 \pm 0.6$ & $1.8 \pm 0.2$ & $0.39 \pm 0.01$ \\
\hline
\end{tabular}

ity displayed by the samples built in the longitudinal direction. Table 8 shows all the results obtained testing these specimens.

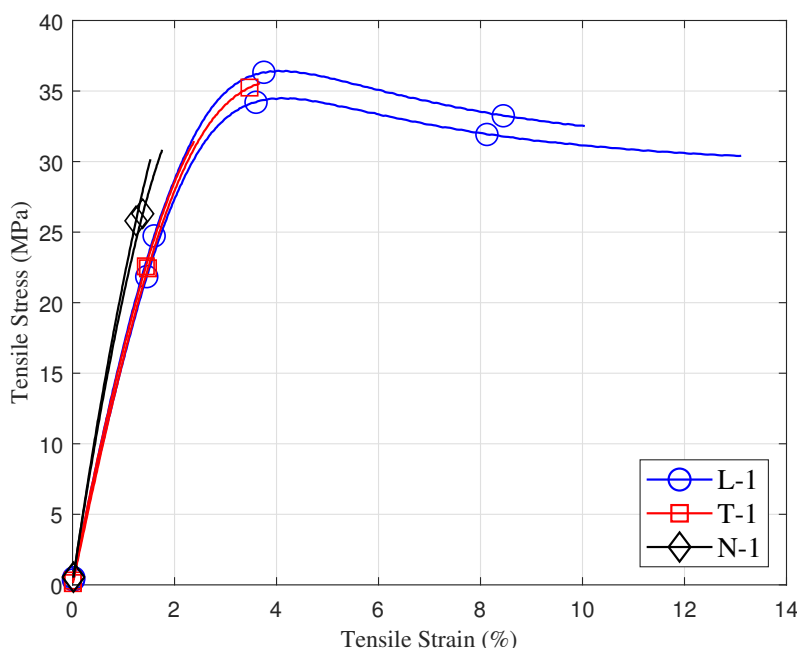

Fig. 14 Stress-strain curves for ABS families L-1, T-1 and N-1. Effect of the build orientation.

\subsubsection{Layer Thickness}

The influence of the layer thickness is shown in Fig.15. Increasing the number of layers clearly improves the Young's modulus and UTS which are increased by $16 \%$ and $13 \%$ respectively. Table 9 summarizes all the data obtained thanks to the tensile tests performed on the ABS specimens. 


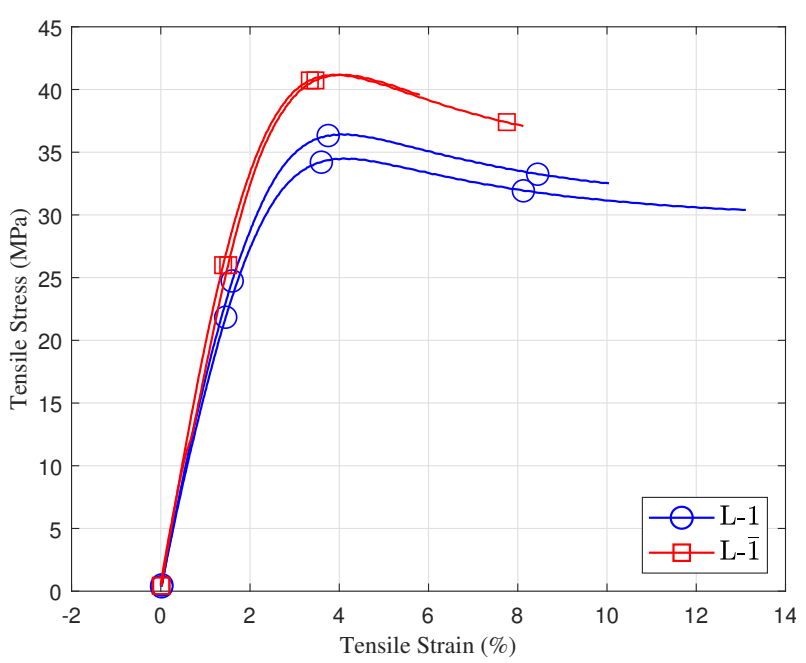

Fig. 15 Stress-strain curves for ABS families L-1 and L-1. Effect of the layer thickness.

Table 9 Average values and standard deviation of Young's modulus, ultimate tensile strength, elongation at break and Poisson's ratio for ABS families L-1 and L-1.

\begin{tabular}{lllll}
\hline $\begin{array}{l}\text { Layer Thickness } \\
\text { ABS }\end{array}$ & $\begin{array}{l}\mathbf{E} \\
(\mathrm{MPa})\end{array}$ & $\begin{array}{l}\text { UTS } \\
(\mathrm{MPa})\end{array}$ & $\begin{array}{l}\text { Elong. break } \\
(\%)\end{array}$ & $\boldsymbol{\nu}$ \\
\hline $\mathbf{L - 1}$ & $1831 \pm 59$ & $35.6 \pm 0.9$ & $13.1 \pm 3.1$ & $0.40 \pm 0.01$ \\
$\mathbf{L - 1}$ & $2131 \pm 65$ & $40.2 \pm 0.9$ & $13.1 \pm 10.8$ & $0.39 \pm 0.01$ \\
\hline
\end{tabular}

Table 10 Average values and standard deviation of Young's modulus, ultimate tensile strength, elongation at break and Poisson's ratio for ABS families L-1, L-2, L-3 and L4.

\begin{tabular}{lllll}
\hline $\begin{array}{l}\text { Post-curing time } \\
\text { ABS }\end{array}$ & $\begin{array}{l}\text { E } \\
(\mathrm{MPa})\end{array}$ & $\begin{array}{l}\text { UTS } \\
(\mathrm{MPa})\end{array}$ & $\begin{array}{l}\text { Elong. break } \\
(\%)\end{array}$ & $\boldsymbol{\nu}$ \\
\hline $\mathbf{L - 1}$ & $1831 \pm 59$ & $35.6 \pm 0.9$ & $13.1 \pm 3.1$ & $0.40 \pm 0.01$ \\
L-2 & $1947 \pm 11$ & $38.9 \pm 1.1$ & $13.9 \pm 6.1$ & $0.40 \pm 0.02$ \\
L-3 & $1968 \pm 106$ & $40.8 \pm 0.9$ & $13.0 \pm 3.9$ & $0.40 \pm 0.01$ \\
L-4 & $1997 \pm 145$ & $46 \pm 0.4$ & $13.7 \pm 4.3$ & $0.35 \pm 0.03$ \\
\hline
\end{tabular}

\subsubsection{Post-curing time}

In Fig.16 the stress-strain curves are shown to study the influence of the postcuring process on this resin. The curves show a regular increase of the UTS with exposure time while the Young's modulus and elongation at break, as shown in Table 10, are almost constant. The curves' shape shows, also for this resin, a strain softening behaviour of the material. Fig.17 and Fig.18 show the UTS and Young's modulus value as a function of the post-processing time. It is clear that increasing the post-curing time improves all the mechanical properties. 


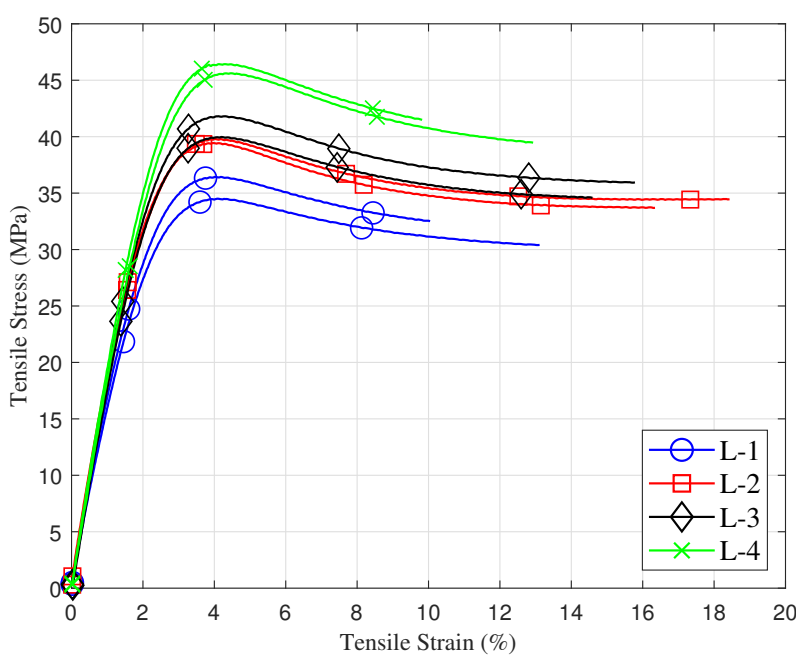

Fig. 16 Stress-strain curves for ABS families L-1, L-2, L-3 and L4. Effect of the post-curing time.

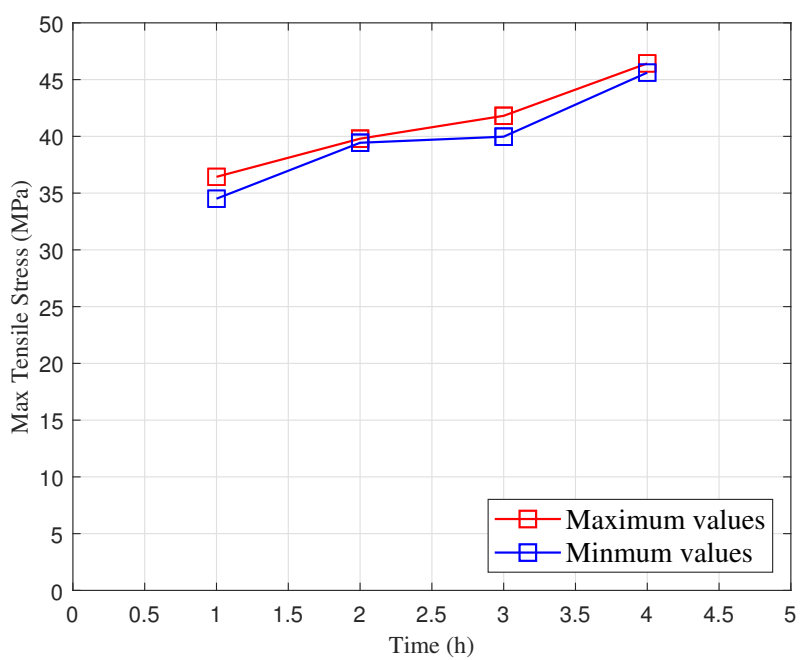

Fig. 17 Evolution of the ultimate tensile strength as a function of the exposition time for ABS

\section{Discussion}

The results show the influence of the manufacturing factors on the mechanical properties at different levels, depending on the studied resin. Fig.19, Fig.20, Fig.21 display the mean value of UTS, Young's modulus and elongation at break for all the studied families.

Tested S-PRO specimens show well-balanced tough and fragile mechanical properties. This resin shows a strong dependence on the build orientation. In fact, it is possible to achieve an improvement of approximately $20 \%$ of the Young's modulus and UTS with the transverse configuration (printing along the $\mathrm{x}$ direction), 


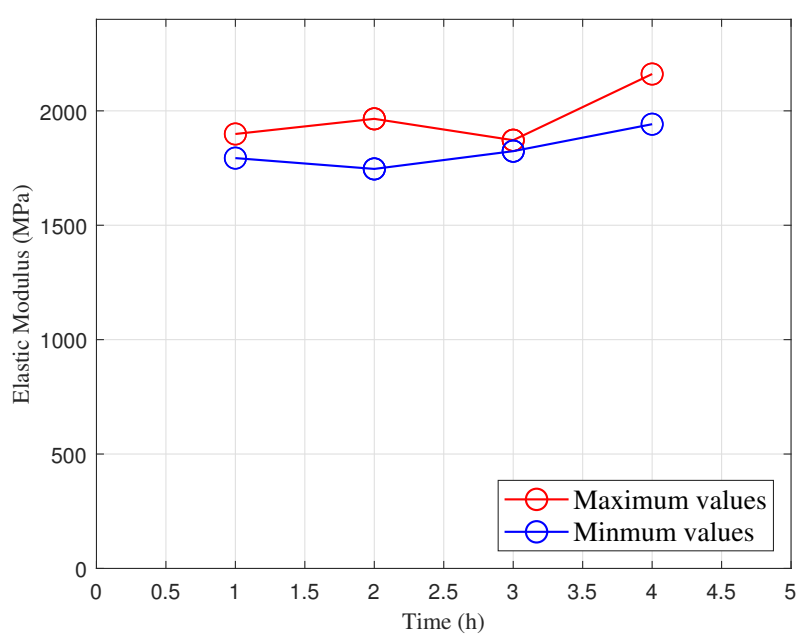

Fig. 18 Evolution of Young's modulus as a function of the exposition time for ABS.

while there is only a slight improvement of the mechanical characteristics with post-curing time. Furthermore, there is no influence of the layer thickness.

The second type of resin, the X-GREEN, shows a ductile mechanical response. The high elongation obtained in all the tests results from its chemical constitution. In this acrylate based resin, the polyacrylate chains can slither and wiggle past and around each other easily thanks to the absence of the extra methyl group [28]. $\mathrm{X}$-GREEN resin is significantly influenced by all the considered factors. Also, for this resin, the transverse configuration has shown to result in the best mechanical properties, offering an increase of Young's modulus and UTS of approximately $55 \%$ together with a loss of $20 \%$ in the elongation at break. Regarding the layer thickness, in that case, doubling the number of layers increases the values of the Young's modulus and UTS of approximately $14 \%$ and $34 \%$ respectively without any loss in terms of ductility. A continuous increase of all the mechanical properties with the post-curing time is observed from $1 \mathrm{~h}$ to $4 \mathrm{~h}$ with an increase of Young's modulus and UTS of approximately $50 \%$. For this resin, an elongation at break of at least $35 \%$ has been reached for all the configurations so the ductility of this resin is not influenced by the considered factors.

The experimental data for the ABS show a rather brittle resin compared to the other resins. Build orientation plays a fundamental role. The transverse and normal configurations showed brittle behaviour. For all the test executed on the 3 specimens of the two families, the rupture occurred without any plasticity. Both thinner layer thickness and higher post-curing period induce an improvement of the mechanical properties. ABS methacrylate based samples show the highest tensile strength and lowest elongation at break in almost all the analysed cases. They are characterised by significant behaviour change with the building direction. The samples display a tough and fragile behaviour when built in transverse and normal directions, whereas plasticity can develop when built in the longitudinal direction. This is thought to result from the manufacturing process :

- Samples from family T-1 (transverse direction) are characterized by a very discretized geometry in the rounded zone of the specimen, which results in 
sudden cross-section changes and thus in huge stress-concentration. Rupture is always found to occur in this area.

- Samples from family N-1 (normal direction) are contrarily geometrically very well defined. However, separating the printed sample from the printer base requires to make use of a razor blade which inevitably introduces scratches at the specimen surface. Rupture has been found to initiate at these scratches which thus explain the observed brittle behaviour.

- Only samples build in the longitudinal direction are free of added geometrical defects resulting from the processing so that plasticity can develop only in these samples.

This behaviour change with the building orientation is thus thought to be a good illustration of the particular role of processing on the resulting mechanical properties of 3D-printed specimens.

The build orientation strongly influences the UTS and Young's modulus [12]. According to [17], the thinner the layer the higher the UTS and Young's modulus. Lastly, even the post-curing time showed to be responsible for the change in mechanical properties. The results agreed with [19] showing how also in PSL-parts the importance of the post-curing time.

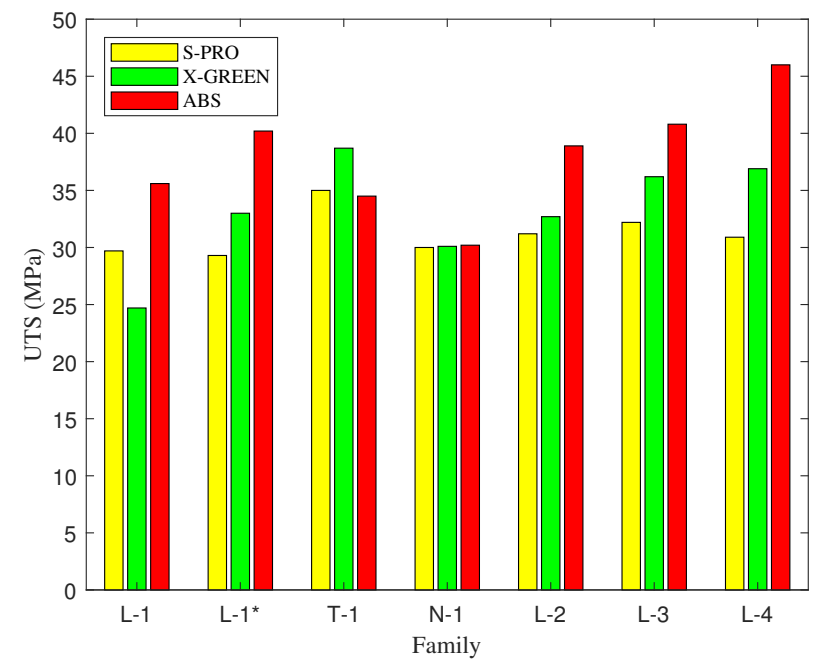

Fig. 19 Mean value of the ultimate tensile strength for all the families.

\section{Conclusions}

In this study, the influence of build orientation, layer thickness and post-curing time on the mechanical properties of parts obtained from different resins with PSL technique has been presented. Analyzing the results individually on each resin, in accordance with their behaviour known from the information provided by suppliers, the following different responses occurred: 


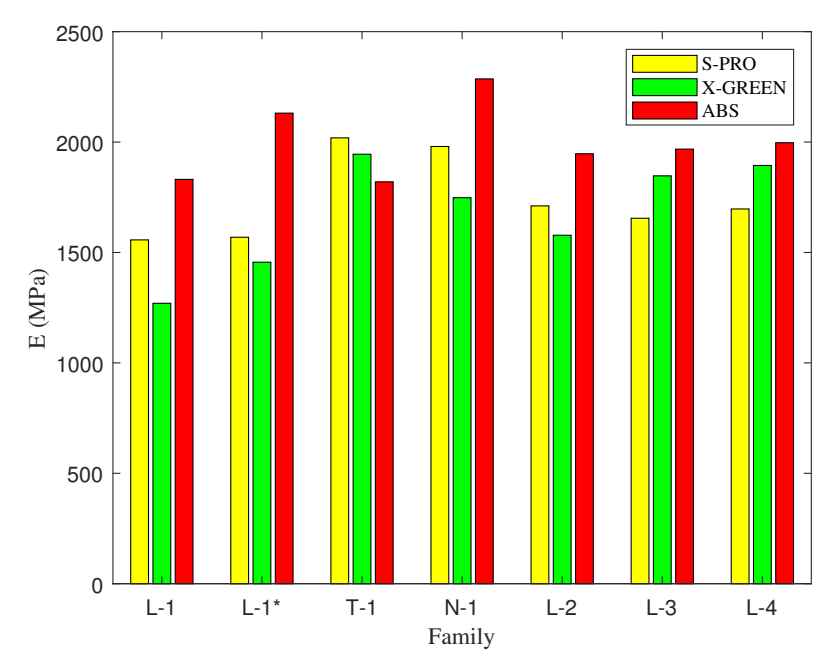

Fig. 20 Mean value of the Young's modulus for all the families.

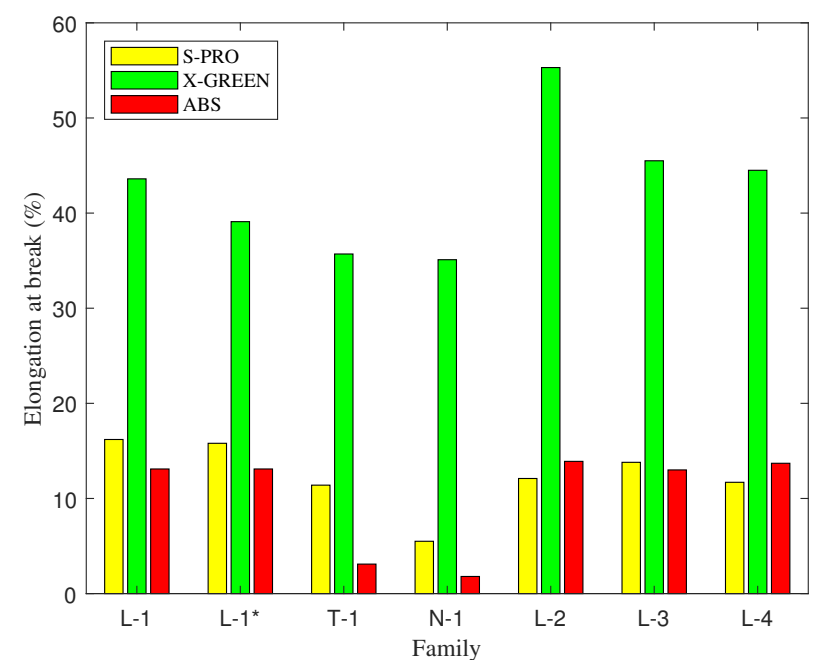

Fig. 21 Mean value of the elongation at break for all the families.

- S-PRO has shown to be quite stable, with an effect on the mechanical properties only of the build orientation ( $\mathrm{L}-1 \rightarrow \mathrm{T}-1$ ), with a noticeable increase on the UTS and Young's modulus with a slight decrease in elongation at break;

- X-GREEN, always keeping at least 35\% of elongation at break, showed to be strongly influenced by all the factors with a significant increase in UTS and Young's modulus changing the build orientation (L-1 $\rightarrow \mathrm{T}-1$ ) and increasing the post-curing time (L-1 $\rightarrow$ L-4). Also, the layer thickness affected tensile tests confirming that the smaller the layer, the higher the mechanical properties of the part;

- ABS brittle behaviour was confirmed, with a strong effect of the build orientation, with the breakage of the specimens that occurred before the develop- 
ment of the plastic regime in the transverse and normal configuration. On the other hand, increasing the post-curing time (L-1 $\rightarrow$ L-4) and decreasing the layer thickness $(\mathrm{L}-1 \rightarrow \mathrm{L}-\overline{1})$, an improvement in UTS and Young's modulus occurred.

Overall, the build orientation showed a stronger influence on the mechanical properties independently of the used resin. Layer thickness and post-curing time influenced X-GREEN and ABS resins in a similar way, although with a different percentage increase, while they did not affect S-PRO, which showed the most stable behaviour among the three.

In conclusion, although some common trends between the influences of the various factors on the mechanical properties have been observed, each resin has demonstrated its own particular behaviour in relation to the specific studied parameter. This result, therefore, encourages the mechanical characterization for each new resin needed in a specific application where parts are obtained through PSL.

\section{Acknowledgements}

The authors gratefully acknowledge ERASMUS+ 2017-18 program for funding this project (Grant Agreement No 2017-1-IT02-KA103-035320 - I NAPLES01).

\section{References}

1. I. Gibson, D. W. Rosen and Brent Stucker (2010) Additive Manufacturing Technologies, 61-63, Springer.

2. P. Alexander, S. Allen and D. Duttax (1998), Part orientation and build cost determination in layered manufacturing, Computer-Aided Design, 30 (5), pp. 343-356.

3. J.Y.H. Fuh, L. Lu, C.C. Tan, Z.X. Shen and S. Chew (1999) Curing characteristics of acrylic photopolymer used in stereolithography process, Rapid Prototyping Journal, 5 (1), pp. $27-34$.

4. J.M. Dulieu-Barton and M.C. Fulton (2000) Mechanical Properties of a Typical Stereolithography Resin, Strain, 36 (2).

5. F.P.W. Melchels, J. Feijen and D. W. Grijpma, (2010) A review on stereolithography and its applications in biomedical engineering, Biomaterials, 31, pp. 6121-6130.

6. R. B. Wicker, A. V. Ranade, F. Medina and J. A. Palmer, Embedded micro-channel fabrication using line-scan stereolithography (2005) Assembly Automation, 25(4), pp. 316329.

7. Y. Yang, L. Li, Jing Zhao (2019) Mechanical property modeling of photosensitive liquid resin in stereolithography additive manufacturing: Bridging degree of cure with tensile strength and hardness, Materials and Design, 2019, 162, 418-428

8. A. Bertsch, P. Bernhard, C. Vogt and P. Renaud (2000) Rapid prototyping of small size objects, Rapid Prototyping Journal, 6, pp.259-266.

9. C. Sun, N. Fang, D.M. Wu and X. Zhang (2005) Projection micro-stereolithography using digital micro-mirror dynamic mask, Sensors and Actuators A, 121, pp. 113-120.

10. M. Mahdi Emami, F. Barazandeh and Farrokh Yaghmaie (2014) Scanning-projection based stereolithography: Method and structure, Sensors and Actuators A: Physical, 218, pp. 116124.

11. J. R. C. Dizon, A. H. Espera, Q. Chen and R. C. Advincul (2018) Mechanical characterization of 3D-printed polymers, Additive Manufacturing, 20, 44-67.

12. R. Quintana, J.-W. Choi, K. Puebla and R. Wicker (2010), Effects of build orientation on tensile strength for stereolithography-manufactured ASTM D-63 type I specimens, International Journal of Advanced Manufacturing Technology, 46, pp. 201-215. 
13. G. Domínguez-Rodríguez, J. J. Ku-Herrera and A. Hernández-Pérez (2018), An assessment of the effect of printing orientation, density, and filler pattern on the compressive performance of 3D printed ABS structures by fuse deposition, International Journal of Advanced Manufacturing Technology, 95(5-8).

14. S. Rohde, J. Cantrell, A. Jerez, C. Kroese, D. Damiani, R. Gurnani, L. DiSandro, J. Anton, A. Young, D. Steinbach and P. Ifju (2018), Experimental Characterization of the Shear Properties of 3D-Printed ABS and Polycarbonate Parts. Experimental Mechanics, 58(6), 871-884.

15. S. Abid, R. Messadi, T. Hassine, H. Ben Daly, J. Soulestin, and M. F. Lacrampe (2019) Optimization of mechanical properties of printed acrylonitrile butadiene styrene using RSM design, International Journal of Advanced Manufacturing Technology, 100(5-8), 1363-1372.

16. J. Jiang, J. Lou and G. Hu (2019) Effect of support on printed properties in fused deposition modelling processes, Virtual and Physical Prototyping, 14:4, 308-315.

17. K. Chockalingam, N. Jawahar and U. Chandrasekhar (2006) Influence of layer thickness on mechanical properties in stereolithography, Rapid Prototyping Journal, 12 (2), pp. 106-113.

18. B. Rankouhi, S. Javadpour, F. Delfanian, T. Letcher (2016) Failure analysis and mechanical characterization of 3D printed ABS with respect to layer thickness and orientation, J. Fail. Anal. Prev. 16 (3) 467-481.

19. N. Chantarapanich, P. Puttawibul, K. Sitthiseripratip, S. Sucharitpwatskul and S. Chantaweroad (2013) Study of the mechanical properties of photo-cured epoxy resin fabricated by stereolithography process, Songklanakarin Journal of Science Technology, 35, pp.91-98.

20. R. Hague, (2004) Materials analysis of stereolithography resins for use in rapid manufacturing, J. Mater. Sci. 39 (7) 2457-2464.

21. J. Jiang, J. Stringer, X. Xu, and R. Y. Zhong (2018) Investigation of printable threshold overhang angle in extrusion-based additive manufacturing for reducing support waste. International Journal of Computer Integrated Manufacturing, 31(10), 961-969.

22. J. Jiang, X. Xu and J. Stringer (2019) Optimization of process planning for reducing material waste in extrusion based additive manufacturing. Robotics and Computer-Integrated Manufacturing, 59, 317-325.

23. Material Safety Data Sheet - S-PRO

24. Material Safety Data Sheet - X-GREEN

25. Material Safety Data Sheet - ABS

26. M. Jerabeka, Z. Major and R.W. Lang (2010) Strain determination of polymeric materials using digital image correlation, Polymer Testing, 29, pp. 407-416.

27. David Roylance (2001) Stress-Strain curves,Massachusetts Institute of Technology, Department of Materials Science and Engineering.

28. D. K. Chattopadhyay, S. Sankar Panda and K. V. S. N. Raju (2005) Thermal and mechanical properties of epoxy acrylate/methacrylates UV cured coatings, Progress in Organic Coatings, 54 (1), pp. 10-19. 


\section{Appendix}

Table 11 Percentage variation of E, UTS and elongation at break for S-PRO families L-1, T-1 and N-1

\begin{tabular}{llll}
\hline E variation (\%) & L-1 & T-1 & N-1 \\
\hline L-1 & - & -29.7 & -27.2 \\
T-1 & +29.7 & - & +1.9 \\
N-1 & +27.2 & -1.9 & - \\
\hline UTS variation (\%) & $\mathbf{L - 1}$ & $\mathbf{T - 1}$ & $\mathbf{N - 1}$ \\
\hline L-1 & - & -17.8 & -0.8 \\
T-1 & +17.8 & - & +16.7 \\
N-1 & +0.8 & -16.7 & - \\
\hline Elong. at break variation (\%) & $\mathbf{L - 1}$ & $\mathbf{T}-\mathbf{1}$ & $\mathbf{N}-\mathbf{1}$ \\
\hline L-1 & - & +42.2 & +192.4 \\
T-1 & -42.2 & - & +105.6 \\
N-1 & -192.4 & -105.6 & - \\
\hline
\end{tabular}

Table 12 Percentage variation of E, UTS and elongation at break for S-PRO families L-1 and L- $\overline{1}$

\begin{tabular}{|c|c|c|}
\hline E variation (\%) & L-1 & $\mathbf{L}-\overline{\mathbf{1}}$ \\
\hline L-1 & - & +1.5 \\
\hline $\mathbf{L - \overline { 1 }}$ & -1.5 & - \\
\hline UTS variation (\%) & L-1 & $\mathbf{L}-\overline{\mathbf{1}}$ \\
\hline L-1 & - & -0.8 \\
\hline $\mathbf{L -} \overline{\mathbf{1}}$ & +0.8 & - \\
\hline Elong. at break variation (\%) & L-1 & $\mathbf{L}-\overline{\mathbf{1}}$ \\
\hline L-1 & - & -2.3 \\
\hline L- $\overline{\mathbf{1}}$ & +2.3 & - \\
\hline
\end{tabular}


Table 13 Percentage variation of E, UTS and elongation at break for S-PRO families L-1, L-2, L-3 and L-4

\begin{tabular}{lllll}
\hline E variation (\%) & L-1 & L-2 & L-3 & L-4 \\
\hline L-1 & - & -9.9 & -6.3 & -8.9 \\
L-2 & +9.9 & - & +3.4 & +0.8 \\
L-3 & +6.3 & -3.4 & - & -2.5 \\
L-4 & +8.9 & -0.8 & +2.5 & - \\
\hline UTS variation (\%) & L-2 & L-3 & L-4 & \\
\hline L-1 & - & -4.9 & -8.2 & -4.0 \\
L-2 & +4.9 & - & -3.1 & +0.9 \\
L-3 & +8.2 & +3.1 & - & +4.0 \\
L-4 & +4.0 & -0.9 & -4.0 & - \\
\hline Elong. at break variation (\%) & L-1 & L-2 & L-3 & L-4 \\
\hline L-1 & - & +33.6 & +19.3 & +38.6 \\
L-2 & -33.6 & - & -14.0 & +3.7 \\
L-3 & -19.3 & +14.0 & - & +18.3 \\
L-4 & -38.6 & -3.7 & -18.3 & - \\
\hline
\end{tabular}

Table 14 Percentage variation of E, UTS and elongation at break for X-GREEN families L-1, $\mathrm{T}-1$ and N-1

\begin{tabular}{llll}
\hline E variation (\%) & L-1 & T-1 & N-1 \\
\hline L-1 & - & -53.1 & -37.7 \\
T-1 & +53.1 & - & +11.2 \\
N-1 & +37.7 & -11.2 & - \\
\hline UTS variation (\%) & $\mathbf{L - 1}$ & $\mathbf{T - 1}$ & $\mathbf{N}-\mathbf{1}$ \\
\hline L-1 & - & -56.7 & -21.9 \\
T-1 & +56.7 & - & +28.6 \\
N-1 & +21.9 & -28.6 & - \\
\hline Elong. at break variation (\%) & $\mathbf{L - 1}$ & $\mathbf{T}-\mathbf{1}$ & $\mathbf{N}-1$ \\
\hline L-1 & - & +22.1 & +24.3 \\
T-1 & -22.1 & - & +1.8 \\
N-1 & -24.3 & -1.8 & - \\
\hline
\end{tabular}

Table 15 Percentage variation of E, UTS and elongation at break for X-GREEN families L-1 and L-1

\begin{tabular}{|c|c|c|}
\hline E variation (\%) & L-1 & $\mathbf{L - \overline { 1 }}$ \\
\hline L-1 & - & +14.7 \\
\hline L- $\overline{1}$ & -14.7 & - \\
\hline UTS variation (\%) & L-1 & $\mathbf{L - \overline { 1 }}$ \\
\hline L-1 & - & +33.7 \\
\hline $\mathbf{L}-\overline{\mathbf{1}}$ & -33.7 & - \\
\hline Elong. at break variation (\%) & L-1 & $\mathbf{L}-\overline{1}$ \\
\hline L-1 & - & -11.6 \\
\hline L- $\overline{\mathbf{1}}$ & +11.6 & - \\
\hline
\end{tabular}


Table 16 Percentage variation of E, UTS and elongation at break for X-GREEN families L-1, L-2, L-3 and L-4

\begin{tabular}{lllll}
\hline E variation (\%) & L-1 & L-2 & L-3 & L-4 \\
\hline L-1 & - & -24.3 & -45.4 & -49.2 \\
L-2 & +24.3 & - & -17.0 & -20.0 \\
L-3 & +45.4 & 17.0 & - & -2.5 \\
L-4 & +49.2 & +20.0 & +2.5 & - \\
\hline UTS variation (\%) & L-2 & L-3 & L-4 & \\
\hline L-1 & - & -32.5 & -46.7 & -49.3 \\
L-2 & +32.5 & - & -10.7 & -12.6 \\
L-3 & +46.7 & +10.71 & - & -1.8 \\
L-4 & +49.3 & +12.6 & +1.8 & - \\
\hline Elong. at break variation (\%) & $\mathbf{L - 1}$ & $\mathbf{L - 2}$ & $\mathbf{L - 3}$ & $\mathbf{L - 4}$ \\
\hline L-1 & - & -26.7 & -4.2 & -1.8 \\
L-2 & +26.7 & - & +21.6 & +24.3 \\
L-3 & +4.2 & -21.6 & - & +2.2 \\
L-4 & +1.8 & -24.3 & -2.2 & - \\
\hline
\end{tabular}

Table 17 Percentage variation of E, UTS and elongation at break for ABS families L-1, T-1 and N-1

\begin{tabular}{llll}
\hline E variation (\%) & L-1 & T-1 & N-1 \\
\hline L-1 & - & +0.6 & -24.8 \\
T-1 & -0.6 & - & -25.6 \\
N-1 & +24.8 & +25.6 & - \\
\hline UTS variation (\%) & L-1 & T-1 & N-1 \\
\hline L-1 & - & +3.1 & +17.8 \\
T-1 & -3.1 & - & -14.3 \\
N-1 & -17.8 & +14.3 & - \\
\hline Elong. at break variation $\mathbf{( \% )}$ & $\mathbf{L - 1}$ & $\mathbf{T - 1}$ & $\mathbf{N - 1}$ \\
\hline L-1 & - & +317.6 & +646.9 \\
T-1 & -317.6 & - & +75.8 \\
N-1 & -646.9 & -75.8 & - \\
\hline & & &
\end{tabular}

Table 18 Percentage variation of E, UTS and elongation at break for ABS families L-1 and $\mathrm{L}-\overline{1}$

\begin{tabular}{|c|c|c|}
\hline E variation (\%) & L-1 & L- $\overline{1}$ \\
\hline L-1 & - & +16.3 \\
\hline L-⿳亠丷厂二⿺ & -16.3 & - \\
\hline UTS variation (\%) & L-1 & $\mathbf{L}-\overline{\mathbf{1}}$ \\
\hline L-1 & - & +13.0 \\
\hline $\mathbf{L}-\overline{\mathbf{1}}$ & -13.0 & - \\
\hline Elong. at break variation (\%) & L-1 & $\mathbf{L}-\overline{\mathbf{1}}$ \\
\hline L-1 & - & +0.5 \\
\hline $\mathbf{L}-\overline{\mathbf{1}}$ & -0.5 & - \\
\hline
\end{tabular}


1

Table 19 Percentage variation of E, UTS and elongation at break for ABS families L-1, L-2, L-3 and L-4

\begin{tabular}{lllll}
\hline E variation (\%) & L-1 & L-2 & L-3 & L-4 \\
\hline L-1 & - & -6.3 & -7.5 & -9.0 \\
L-2 & +6.3 & - & -1.1 & -2.5 \\
L-3 & +7.5 & +1.1 & - & -1.4 \\
L-4 & +9.0 & +2.5 & +1.4 & - \\
\hline UTS variation (\%) & L-2 & L-3 & L-4 & \\
\hline L-1 & - & -9.6 & -14.8 & -29.2 \\
L-2 & +9.6 & - & -4.8 & -17.7 \\
L-3 & +14.8 & +4.8 & - & -12.7 \\
L-4 & +29.2 & +17.7 & +12.7 & - \\
\hline Elong. at break variation $(\%)$ & $\mathbf{L - 1}$ & $\mathbf{L - 2}$ & $\mathbf{L - 3}$ & $\mathbf{L - 4}$ \\
\hline L-1 & - & -6.1 & +0.5 & -4.6 \\
L-2 & +6.1 & - & +6.7 & +1.4 \\
L-3 & -0.5 & -6.7 & - & -5.4 \\
L-4 & +4.6 & -1.4 & +5.4 & - \\
\hline
\end{tabular}


Click here to download Figure Figure4.png $\stackrel{ \pm}{*}$

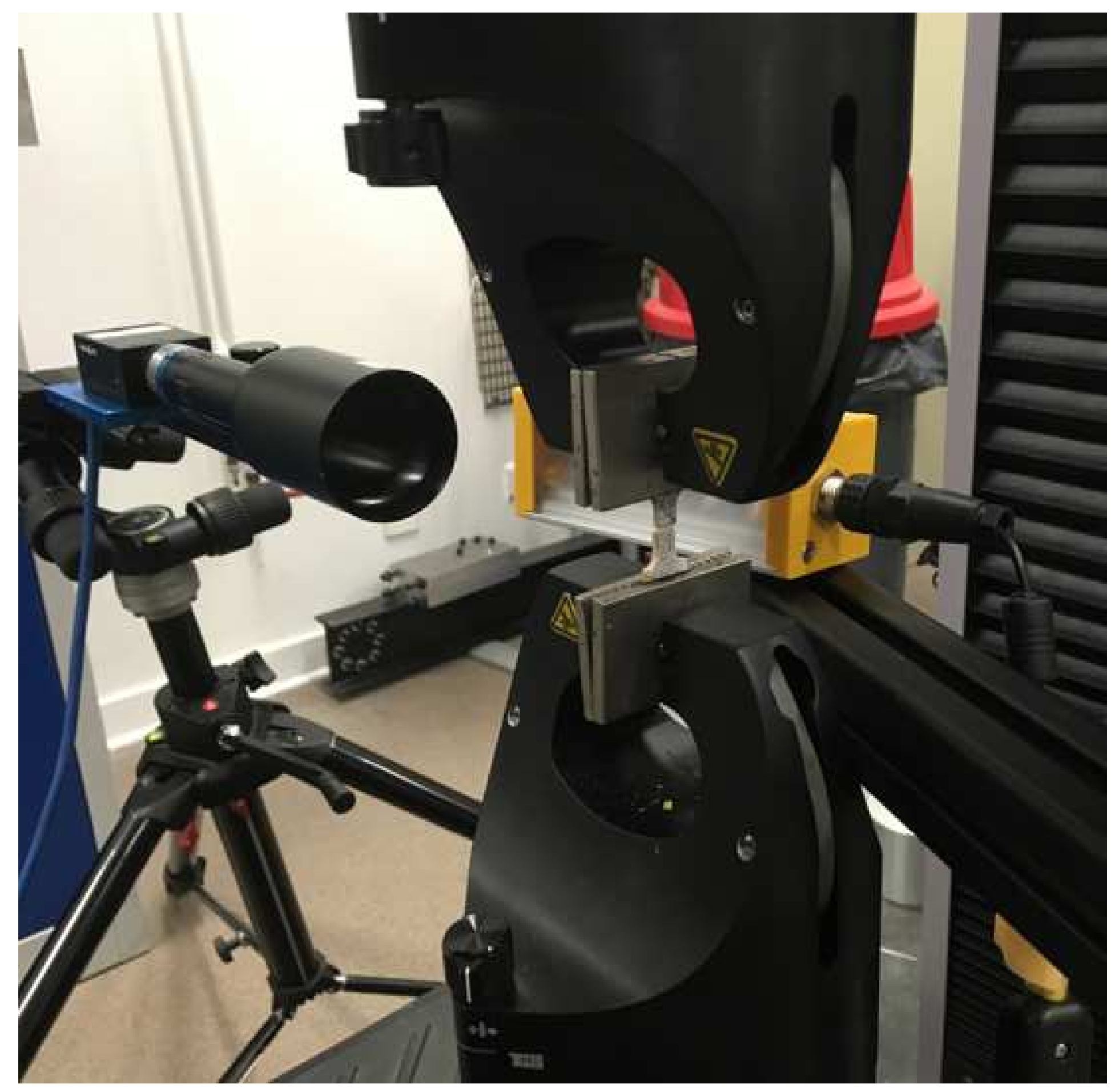



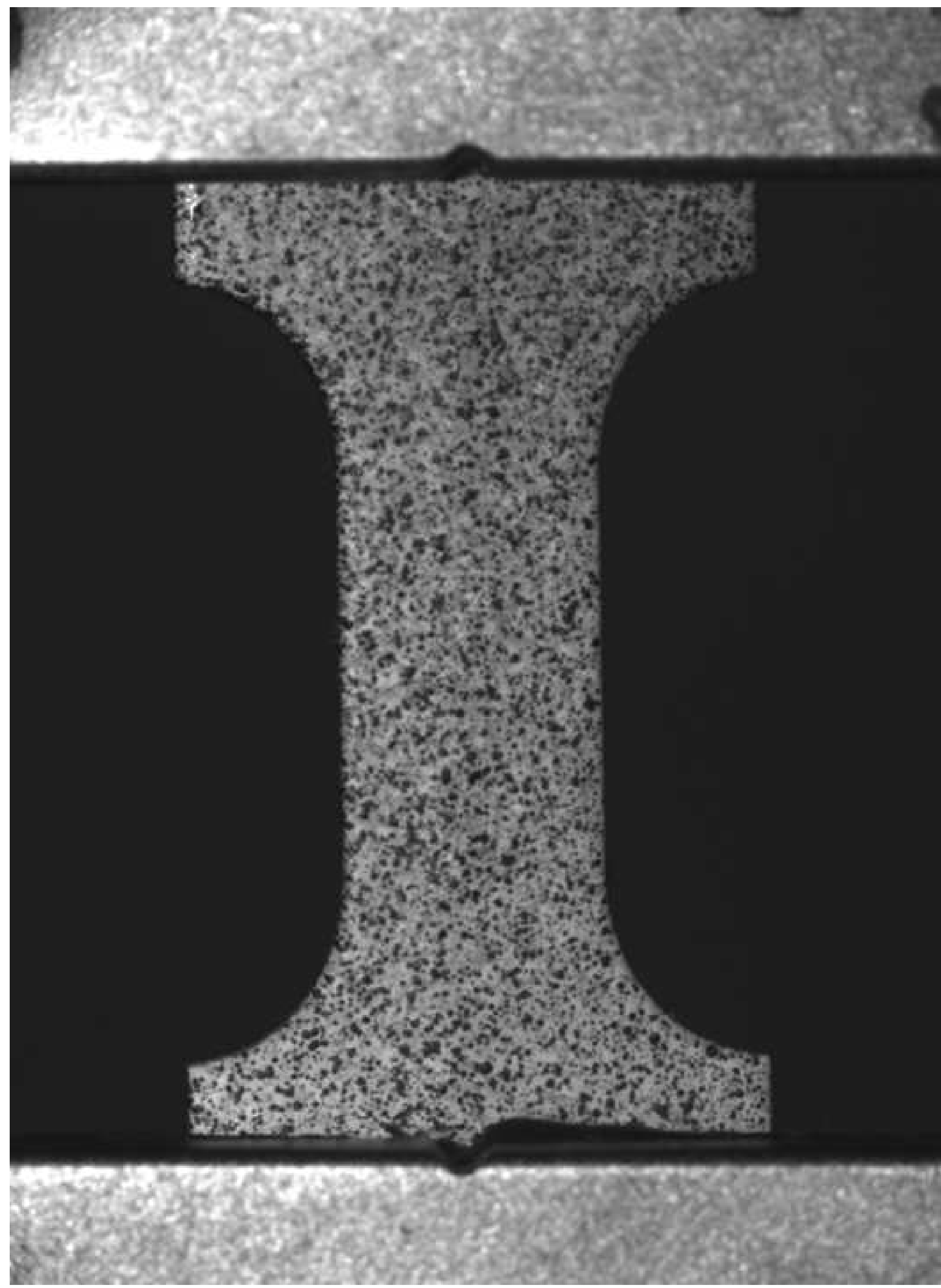
Click here to access/download Supplementary Material manuscript.pdf 